\title{
Strategies to improve the dietary quality of Supplemental Nutrition Assistance Program (SNAP) beneficiaries: an assessment of stakeholder opinions
}

\author{
Susan J Blumenthal ${ }^{1, *}, t$, Elena E Hoffnagle ${ }^{2} \uparrow$, Cindy W Leung ${ }^{3, *},+$, Hayley Lofink ${ }^{4}$, \\ Helen H Jensen ${ }^{5}$, Susan B Foerster ${ }^{6}$, Lilian WY Cheung ${ }^{7}$, Marion Nestle ${ }^{8}$ and \\ Walter C Willett ${ }^{7,9}$ \\ ${ }^{1}$ New America Foundation, 1899 L Street, NW - Suite 400, Washington, DC 20036, USA: ${ }^{2}$ National League \\ of Cities, Washington, DC, USA: ${ }^{3}$ Center for Health and Community, School of Medicine, University of \\ California, San Francisco, 3333 California Street - Suite 465, San Francisco, CA 94118, USA: ${ }^{4}$ School-Based \\ Health Alliance, Washington, DC, USA: ${ }^{5}$ Department of Economics, lowa State University, Ames, IA, USA: \\ ${ }^{6}$ Center for the Study of the Presidency and Congress, Washington, DC, USA: ${ }^{7}$ Department of Nutrition, \\ Harvard School of Public Health, Boston, MA, USA: ${ }^{8}$ Department of Nutrition, Food Studies and Public Health, \\ New York University, New York, NY, USA: ' Department of Epidemiology, Harvard School of Public Health, \\ Boston, MA, USA
}

Submitted 27 March 2013: Final revision received 1 August 2013: Accepted 23 September 2013: First published online 8 November 2013

\begin{abstract}
Objective: To examine the opinions of stakeholders on strategies to improve dietary quality of Supplemental Nutrition Assistance Program (SNAP) participants. Design: Participants answered a thirty-eight-item web-based survey assessing opinions and perceptions of SNAP and programme policy changes.

Setting: USA.

Subjects: Survey of 522 individuals with stakeholder interest in SNAP, conducted in October through December 2011.

Results: The top three barriers to improving dietary quality identified were: (i) unhealthy foods marketed in low-income communities; (ii) the high cost of healthy foods; and (iii) lifestyle challenges faced by low-income individuals. Many respondents (70\%) also disagreed that current SNAP benefit levels were adequate to maintain a healthy diet. Stakeholders believed that vouchers, coupons or monetary incentives for purchasing healthful foods might have the greatest potential for improving the diets of SNAP participants. Many respondents (78\%) agreed that sodas should not be eligible for purchases with SNAP benefits. More than half (55\%) believed retailers could easily implement such restrictions. A majority of respondents (58\%) agreed that stores should stock a minimum quantity of healthful foods in order to be certified as a SNAP retailer, and most respondents (83\%) believed that the US Department of Agriculture should collect data on the foods purchased with SNAP benefits.

Conclusions: Results suggest that there is broad stakeholder support for policies that align SNAP purchase eligibility with national public health goals of reducing food insecurity, improving nutrition and preventing obesity.
\end{abstract}

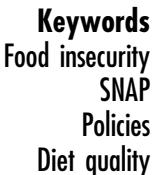

The Supplemental Nutrition Assistance Program (SNAP), formerly known as the Food Stamp Program, is the largest federal food assistance programme in the USA, serving 46.6 million Americans in 2012 at a budget of \$US 78 billion $^{(1)}$. Nearly $50 \%$ of the programme's beneficiaries are children ${ }^{(2)}$. SNAP aims to alleviate food insecurity and improve nutritional status among low-income individuals and households by increasing the resources available to purchase food. Participating households receive benefits through an

$\uparrow$ These authors contributed equally to this work electronic benefit transfer (EBT) card that can be used at authorized food retailers to purchase most foods and beverages except for alcohol, dietary supplements, and hot or prepared foods. In 2012, the average monthly benefit was \$US 133.41 per person ${ }^{(1)}$. In the past 10 years, there has been a $158 \%$ increase in SNAP participation due in part to an economic recession; at the same time, rates of food insecurity have reached record levels ${ }^{(3,4)}$.

Historically, food insecurity in America has been associated with underweight as a result of an inadequate quantity of food intake. But the relationship between 
body weight and food insecurity has grown more complex since the Food Stamp Program was established in 1964 due in part to changes in the food environment over the past 45 years $^{(5)}$. Today food insecurity in America increasingly coincides with obesity and diets of inadequate quality for optimal health. Some cross-sectional studies show associations between SNAP participation and poorer diet quality among low-income adults; few longitudinal studies are available ${ }^{(6,7)}$.

In recent years, Congressional legislation has addressed the need to improve nutritional health among individuals, particularly children, enrolled in federal food assistance programmes. The Special Supplemental Nutrition Program for Women, Infants, and Children (WIC), established in 1972, was revised in 2009 to provide a defined food package that aligns with the Dietary Guidelines for Americans ${ }^{(8)}$. In addition, the Healthy, Hunger-Free Kids Act of 2010 required that National School Breakfast and Lunch Programs and the Child and Adult Care Food Program be modified to improve the nutritional quality of meals by meeting the Dietary Guidelines as well ${ }^{(9)}$. Although the Food, Conservation, and Energy Act of 2008 (the Farm Bill) changed the name of the Food Stamp Program to the Supplemental Nutrition Assistance Program (SNAP) in part to increase the focus on nutrition, this name change was not coupled with the enactment of policies to improve the nutritional intake of programme participants ${ }^{(10)}$.

Individuals with stakeholder interest in SNAP from academia, advocacy groups, government, health care and the food industry may have varied views about existing SNAP policies. The extent to which there is agreement among key stakeholders on strategies for modifying SNAP policies to strengthen nutrition in the programme is critical as this will influence the political feasibility and likelihood of such changes. The objectives of the present study were to assess the opinions of a broad range of SNAP stakeholders concerning (i) barriers to purchasing nutrient-dense, healthy foods within the current structure of SNAP and (ii) the perceived effectiveness of a wide variety of strategies proposed to improve the nutritional status of programme beneficiaries as well as to prevent obesity among SNAP participants.

\section{Methods}

\section{Survey population}

The research team identified a broad spectrum of individuals working on issues related to SNAP, public health, obesity, nutrition and food insecurity. The list included: state and local SNAP directors; directors of the SNAP nutrition education programme (SNAP-Ed); directors of state obesity prevention programmes and community-based obesity projects funded by the Centers for Disease Control and Prevention; leaders from anti-hunger, agricultural policy, health care and advocacy organizations; academia; and representatives of food manufacturing and retail companies. Their contact information was collected through colleagues working in these fields and through university, government, industry and organizations' websites. The final list included 1250 individuals.

\section{Survey design}

The convenience sample of 1250 respondents was asked to complete a thirty-eight-item web-based survey. The survey questions were developed from themes that emerged from interviews with twenty-seven key informants conducted in 2011, where they discussed existing challenges for SNAP participants to access nutritious foods and proposed ideas about policies implemented at the individual, retailer and government levels to improve the nutritional status of SNAP participants ${ }^{(11)}$.

The survey question format varied and included a 5-point Likert scale, yes/no and multiple-choice questions. Survey respondents were asked their opinions about how much emphasis should be placed on: nutrition in the programme; SNAP benefit amounts and frequency of benefit distribution; perceptions of existing barriers and strategies to improving nutrition in the programme; and attitudes towards imposing restrictions on as well as providing incentives for the purchase of various food items. Survey respondents were also asked to share their opinions on: mechanisms to improve the retail food environment and steps to strengthen SNAP-Ed; the collection of data about foods purchased with programme benefits; and the enhanced use of information technology and social media.

The study focused on respondents from five sectors: academia, advocacy groups, government, health care and the food industry. A pilot study was conducted with ten randomly selected survey respondents representing all sectors to evaluate the survey questions for content, clarity and length. Results of the pilot study did not change the content of the survey. The survey was sent by email to 1250 potential respondents through SurveyMonkey ${ }^{\mathrm{TM}}$ between October and December 2011. The survey included an introductory email describing SNAP and the goals of the project, requesting participation and ensuring confidentiality of responses. By continuing with the survey, respondents indicated their consent to take part in the research. Followup emails (occurring two weeks after the initial email) and telephone calls (occurring four weeks after the initial email) were made to non-respondents. A total of 522 individuals completed the survey out of 1250 individuals initially contacted, for an overall response rate of $42 \%$. The study protocol was considered exempt by the Harvard School of Public Health Institutional Review Board.

\section{Statistical analysis}

Stakeholders' opinions and perceptions about SNAP were assessed in the overall study population and stratified by respondents' sector. The $\chi^{2}$ test and ANOVA were conducted to determine whether significant differences 
existed in the patterns of responses by sector. Individuals with missing sector information were excluded from hypothesis tests, although their responses were preserved in the overall study population. All statistical analyses were performed using the statistical software package Stata/IC $12 \cdot 0$.

\section{Results}

Respondents classified themselves as representing a variety of sectors: $19 \%$ worked in academia ( $n 100), 26 \%$ worked at an advocacy/non-profit organization ( $n$ 134), $26 \%$ worked in state/local/federal government ( $n$ 135), $16 \%$ worked in a health care or public health field ( $n$ 84) and $5 \%$ worked in the food industry, food retail or farmers' markets ( $n$ 25; Table 1 ).

Results are reported across all stakeholder groups, organized by survey theme. Because respondents were not required to complete each question, sample sizes varied across questions.

\section{General attitudes about SNAP}

Respondents ranked several aspects of SNAP. The most highly ranked purpose of SNAP was to 'alleviate food insecurity' (mean ranking: $8 \cdot 5$ out of 10 ), followed by to 'ensure adequate dietary intake' (mean: $7 \cdot 4$ out of 10 ) and to 'improve nutrition and overall health' (mean: $7 \cdot 4$ out of 10; Table 2), but $70 \%$ of respondents disagreed that the current level of SNAP benefits was adequate to maintain a healthy diet. Sixty per cent of respondents viewed SNAP as a stimulus for the economy.

Most respondents (77\%) believed that foods purchased with SNAP benefits should be consistent with the Dietary Guidelines for Americans, and more than half (54\%) thought that SNAP should be reformulated into a defined food package containing nutritious foods similar to the WIC. Respondents from health care and the public health sector were most likely to agree that foods purchased with SNAP benefits should be consistent with national nutrition guidelines $(P=0 \cdot 049)$. Across all sectors, $44 \%$ of respondents agreed that SNAP benefits should be distributed twice per month rather than once, which is the current frequency of allocation, and most respondents (87\%) agreed that additional SNAP benefits should be provided to families with school-aged children during the summer, when children are less likely to have access to free- or reduced-price school meals (data not shown).

\section{Barriers and strategies to improving nutrition for SNAP participants}

Respondents identified barriers that influence the nutrition of SNAP participants and incentives that may encourage programme beneficiaries to purchase healthier foods (Table 3). The top three barriers to improving nutrition were: (i) unhealthy foods heavily marketed in
Table 1 Characteristics of the survey respondents $(n 522)$ with stakeholder interest in SNAP, October-December 2011

\begin{tabular}{lrr}
\hline & $n$ & $\%$ \\
\hline Primary sector & & \\
Academia & 100 & 19 \\
Advocacy/non-profit & 134 & 26 \\
Government & 135 & 26 \\
Health care & 84 & 16 \\
Industry/retailer/farmers' market & 25 & 5 \\
Multi-sector & 17 & 3 \\
Other & 27 & 5 \\
Geographic region & & \\
National & 60 & 12 \\
West & 111 & 21 \\
Midwest & 86 & 17 \\
Northeast & 118 & 23 \\
South & 140 & 27 \\
Pacific & 3 & 1 \\
Years of experience in SNAP & & \\
0-2 years & 59 & 11 \\
3-5 years & 77 & 15 \\
6-10 years & 94 & 18 \\
11-15 years & 74 & 14 \\
16-20 years & 41 & 8 \\
21+ years & 92 & 18 \\
I do not work on SNAP & 82 & 16 \\
\hline
\end{tabular}

SNAP, Supplemental Nutrition Assistance Program.

low-income communities (55\%); (ii) the high cost of healthy foods (e.g. fruits and vegetables; 50\%); and (iii) other lifestyle challenges such as stress and time constraints that are frequently faced by low-income individuals and families (47\%).

The two incentives perceived to have the greatest potential to improve the diets of SNAP recipients were to provide vouchers and/or coupons given for the purchase of healthy foods (mean ranking: 8.7 out of 10) and monetary incentives added to the EBT card to purchase fruits and vegetables (mean: $8 \cdot 6$ out of 10 ). Modifying the list of eligible foods that can be purchased with SNAP benefits was also perceived as a method to improve nutrition among recipients. The majority of respondents (78\%) agreed that sodas should not be eligible for purchase with SNAP benefits; there was no significant difference between sectors. Additionally, 74\% agreed that other 'foods of low nutritional value' should be removed from the list of eligible foods under SNAP. When prompted which foods or beverages should be restricted, the three top items were (i) soda (non-diet), (ii) candy and (iii) other sugar-sweetened beverages (such as fruit punch or lemonade). Many respondents (55\%) believed it would be 'easy' for retailers to implement such changes.

\section{Improving the retail food environment for SNAP participants}

Respondents rated increasing the availability of healthy food options in retail outlets in low-income communities as the change to the food environment that would have the greatest impact on improving the nutritional status of SNAP participants (mean ranking: $7 \cdot 9$ out of 10 ; Table 4 ). 
Table 2 General attitudes about SNAP of the survey respondents ( $n$ 522) with a stakeholder interest, October-December 2011

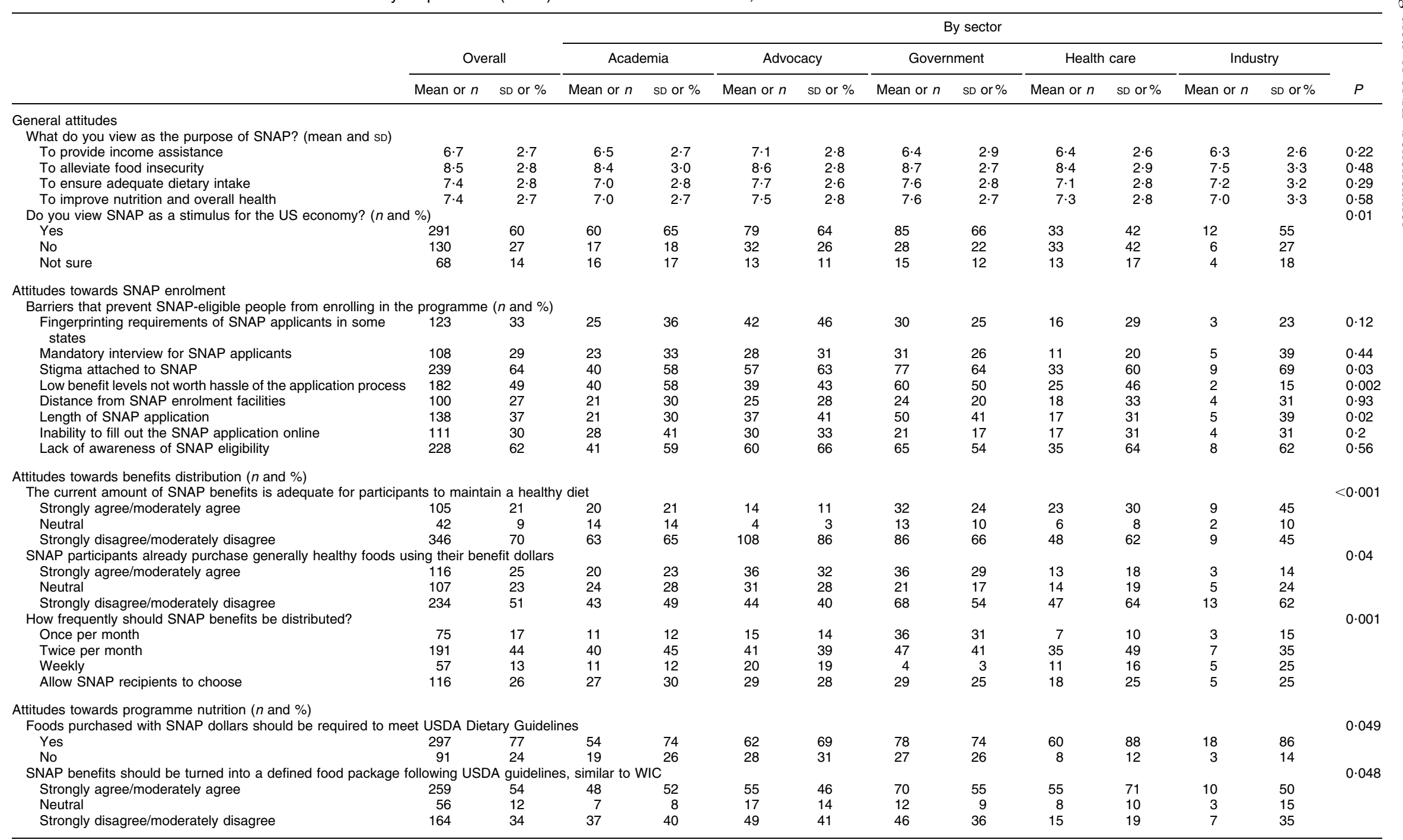

SNAP, Supplemental Nutrition Assistance Program; USDA, US Department of Agriculture; WIC, Special Supplemental Nutrition Program for Women, Infants, and Children. 
Table 3 Barriers and strategies to improving nutrition for SNAP participants according to survey respondents $(n$ 522) with a stakeholder interest, October-December 2011

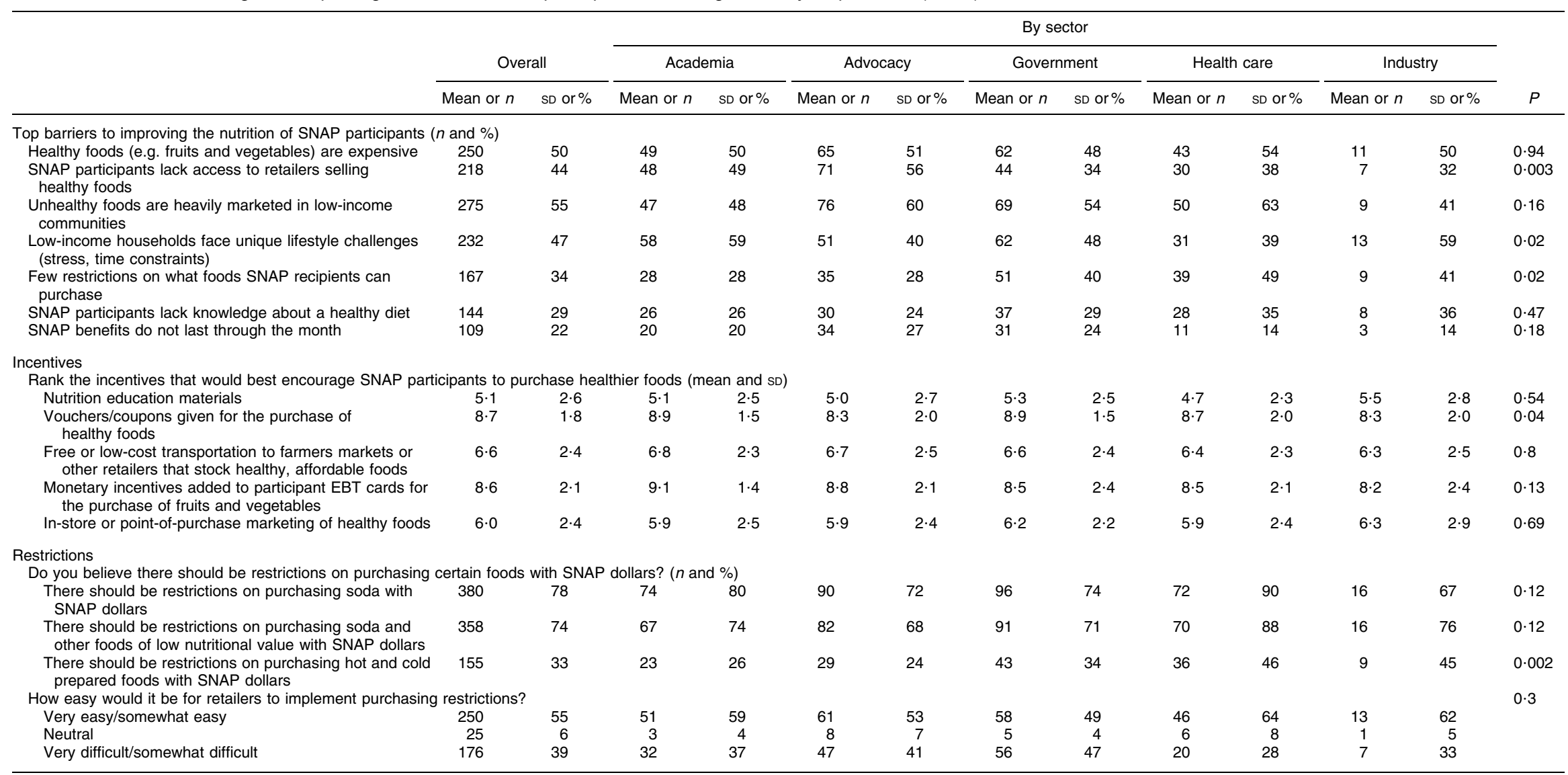

SNAP, Supplemental Nutrition Assistance Program; EBT, electronic benefit transfer. 
Table 4 Strategies for improving the retailer food environment for SNAP participants according to survey respondents ( $n$ 522) with a stakeholder interest, October-December 2011

\begin{tabular}{|c|c|c|c|c|c|c|c|c|c|c|c|c|c|}
\hline & \multirow{2}{*}{\multicolumn{2}{|c|}{ Overall }} & \multicolumn{10}{|c|}{ By sector } & \multirow[b]{3}{*}{$P$} \\
\hline & & & \multicolumn{2}{|c|}{ Academia } & \multicolumn{2}{|c|}{ Advocacy } & \multicolumn{2}{|c|}{ Government } & \multicolumn{2}{|c|}{ Health care } & \multicolumn{2}{|c|}{ Industry } & \\
\hline & Mean or $n$ & SD or \% & Mean or $n$ & SD or \% & Mean or $n$ & SD or \% & Mean or $n$ & SD or \% & Mean or $n$ & SD or \% & Mean or $n$ & SD or \% & \\
\hline \multicolumn{14}{|c|}{ Rank the changes to the retail food environment that would most positively benefit SNAP participants (mean and SD) } \\
\hline Assist small retailers in purchasing healthy foods in bulk & 6.4 & $2 \cdot 5$ & $6 \cdot 7$ & $2 \cdot 6$ & $6 \cdot 2$ & 2.5 & $6 \cdot 6$ & $2 \cdot 4$ & $6 \cdot 1$ & $2 \cdot 2$ & $5 \cdot 3$ & $2 \cdot 8$ & 0.21 \\
\hline $\begin{array}{l}\text { Create strict requirements for certifying stores as } \\
\text { SNAP retailers }\end{array}$ & $5 \cdot 6$ & $2 \cdot 8$ & $5 \cdot 0$ & $2 \cdot 3$ & $5 \cdot 7$ & $2 \cdot 9$ & $5 \cdot 9$ & $2 \cdot 8$ & $6 \cdot 0$ & $3 \cdot 2$ & $6 \cdot 1$ & 3.5 & $0 \cdot 16$ \\
\hline $\begin{array}{l}\text { Incentivize the establishment of retail outlets stocking } \\
\text { healthy options in low-income communities }\end{array}$ & $7 \cdot 9$ & $2 \cdot 4$ & $8 \cdot 2$ & $2 \cdot 2$ & $8 \cdot 0$ & $2 \cdot 3$ & $7 \cdot 8$ & 2.5 & $7 \cdot 6$ & $2 \cdot 4$ & $8 \cdot 1$ & $1 \cdot 7$ & 0.63 \\
\hline $\begin{array}{l}\text { Increase participation in Community Sponsored } \\
\text { Agriculture, Farm to School, and/or community gardens }\end{array}$ & $6 \cdot 1$ & $2 \cdot 8$ & $6 \cdot 0$ & $2 \cdot 6$ & $6 \cdot 2$ & $2 \cdot 8$ & $5 \cdot 8$ & $2 \cdot 8$ & $6 \cdot 2$ & $2 \cdot 8$ & $6 \cdot 0$ & $2 \cdot 6$ & 0.75 \\
\hline \multicolumn{13}{|c|}{ Which partnership would best increase SNAP participants' access to healthy foods? ( $n$ and \%) } & 0.07 \\
\hline $\begin{array}{l}\text { Support mobile food pantries in collaboration with food } \\
\text { banks or non-profit organizations }\end{array}$ & 76 & 19 & 8 & 10 & 25 & 25 & 16 & 15 & 12 & 18 & 5 & 31 & \\
\hline $\begin{array}{l}\text { Support small stores with the purchase of refrigeration } \\
\text { equipment or bulk purchases of foods }\end{array}$ & 94 & 24 & 20 & 26 & 26 & 26 & 23 & 22 & 14 & 21 & 3 & 19 & \\
\hline $\begin{array}{l}\text { Link SNAP participants with community gardens/gardening } \\
\text { programmes }\end{array}$ & 53 & 13 & 12 & 16 & 4 & 4 & 16 & 15 & 14 & 21 & 3 & 19 & \\
\hline $\begin{array}{l}\text { Work with food distributors to make it easier for retailers to } \\
\text { purchase and stock healthy foods }\end{array}$ & 175 & 44 & 37 & 48 & 44 & 44 & 51 & 48 & 28 & 41 & 5 & 31 & \\
\hline \multicolumn{13}{|c|}{ Should stores be required to stock a minimum quantity of healthy foods in order to be a certified SNAP retailer? ( $n$ and \%) } & 0.92 \\
\hline Yes & 278 & 58 & 52 & 57 & 76 & 62 & 73 & 58 & 42 & 54 & 14 & 67 & \\
\hline No & 29 & 6 & 5 & 5 & 7 & 6 & 9 & 7 & 5 & 6 & 2 & 10 & \\
\hline Depends on mandate structure & 174 & 36 & 35 & 38 & 40 & 33 & 44 & 35 & 31 & 40 & 5 & 24 & \\
\hline \multicolumn{14}{|c|}{ What actions need to be taken to ensure that SNAP participants can use th } \\
\hline Expand the use of EBT cards at farmers' markets & 8.8 & $1 \cdot 8$ & $8 \cdot 8$ & $1 \cdot 6$ & $9 \cdot 0$ & 1.7 & $8 \cdot 8$ & $1 \cdot 9$ & $8 \cdot 6$ & $2 \cdot 1$ & $8 \cdot 4$ & $2 \cdot 1$ & 0.45 \\
\hline Provide transportation to farmers' markets & $6 \cdot 0$ & $2 \cdot 4$ & $5 \cdot 9$ & $2 \cdot 4$ & $6 \cdot 1$ & $2 \cdot 6$ & $6 \cdot 0$ & $2 \cdot 2$ & $5 \cdot 4$ & $2 \cdot 4$ & $5 \cdot 8$ & $2 \cdot 3$ & 0.43 \\
\hline Strategically locate farmers' markets in communities & $7 \cdot 9$ & $2 \cdot 1$ & $7 \cdot 8$ & $1 \cdot 9$ & $8 \cdot 1$ & $1 \cdot 8$ & $7 \cdot 9$ & $2 \cdot 2$ & $7 \cdot 5$ & $2 \cdot 5$ & $7 \cdot 3$ & $2 \cdot 7$ & 0.22 \\
\hline $\begin{array}{l}\text { Incentivize the purchase of fruits and vegetables at } \\
\text { farmers' markets }\end{array}$ & $8 \cdot 2$ & $2 \cdot 2$ & 8.5 & 1.9 & 8.5 & $2 \cdot 0$ & $8 \cdot 2$ & $2 \cdot 3$ & $8 \cdot 2$ & $2 \cdot 2$ & $7 \cdot 7$ & $2 \cdot 8$ & 0.46 \\
\hline Modify the hours and days that farmers' markets are open & $5 \cdot 7$ & $2 \cdot 6$ & $5 \cdot 7$ & $2 \cdot 6$ & $6 \cdot 0$ & $2 \cdot 7$ & $5 \cdot 7$ & $2 \cdot 5$ & $5 \cdot 7$ & $2 \cdot 6$ & 3.9 & $2 \cdot 2$ & 0.03 \\
\hline
\end{tabular}


Over half of survey respondents (58\%) believed that stores should be required to stock a minimum quantity of nutrient-dense foods in order to be a certified SNAP retailer. The second most highly rated proposed change included assisting small retailers to purchase nutrientdense foods in bulk (mean: $6 \cdot 4$ out of 10 ). To improve SNAP participants' access to fresh fruits and vegetables, survey respondents highly ranked expanding the ability to use EBT cards at farmers' markets (mean: $8 \cdot 8$ out of 10 ) and incentivizing the purchase of fruits and vegetables at these venues (mean: $8 \cdot 2$ out of 10 ).

\section{Enbancing nutrition education}

SNAP-Ed is an optional state activity that aims to improve the likelihood that SNAP participants, and other lowincome Americans, will make healthy food choices within a limited budget and choose active lifestyles consistent with the 2010 Dietary Guidelines for Americans ${ }^{(12)}$. The 2010 Healthy, Hunger-Free Kids Act called for changes that included the use of multilevel and public health approaches, and grant funding instead of federal financial participation, or state shared matching funds ${ }^{(9)}$. Furthermore, the SNAP-Ed budget was capped through 2018 at 2009 levels, or about $0.5 \%$ of the overall SNAP budget. Final regulations to implement the statute are pending. While more respondents rated SNAP-Ed as effective rather than ineffective, most (88\%) agreed that SNAP should be updated to align its nutrition information and messaging with other federal nutrition assistance programmes (data not shown). Nearly all respondents (92\%) ranked parents with young children as one of the top three target groups on which SNAP-Ed should focus its messages and resources, followed by elementary school-aged children and adolescents. Additionally, survey respondents had positive attitudes (73\%) regarding increasing the utilization of information technology and social media as educational and outreach tools with SNAP participants (data not shown).

\section{Future research directions}

The majority of respondents (83\%) agreed that the US Department of Agriculture (USDA) should collect detailed information on what foods are purchased with SNAP benefits. However, currently, data collected by individual grocery stores are deemed proprietary and not publicly available.

Respondents prioritized three areas where more research is needed to improve the dietary quality of SNAP recipients: (i) examining the effectiveness of incentives for fruit and vegetable purchases on improving dietary quality among SNAP beneficiaries (mean ranking: $8 \cdot 2$ out of 10); (ii) documenting the link between SNAP participation and children's health outcomes (mean: $8 \cdot 0$ out of 10); and (iii) understanding SNAP participants' ability to access healthy foods in their neighbourhood (mean: $7 \cdot 9$ out of 10 ; data not shown).

\section{Discussion}

The present study of diverse SNAP stakeholders demonstrates both the importance and the complexity of the path forward to improving nutritional status among SNAP recipients in the years ahead. Stakeholder respondents agreed that the principal purposes of SNAP are to alleviate food insecurity, ensure adequate dietary intake, and improve participants' nutrition and overall health. However, the pathway to accomplishing these goals requires the implementation of multiple strategies, including new policies that address food quality (not just the provision of food resources) to reduce food insecurity and disparities in obesity and diet-related chronic disease risk among SNAP participants ${ }^{(13)}$.

Developing innovative strategies for SNAP that simultaneously support good health while combating hunger, obesity and chronic disease risk has proved challenging to date. Recent reports issued by the Institute of Medicine and the Center for the Study of the Presidency and Congress underscore the importance of aligning federal food assistance programmes with the Dietary Guidelines for Americans which includes a goal of limiting excess consumption of energy from added sugars and solid fats in foods and beverages ${ }^{(14,15)}$. The present study shows there is stakeholder support for providing financial incentives for the purchase of fruits and vegetables and for removing sugar-sweetened beverages from the list of eligible foods in SNAP. Research has revealed the negative impact of sugar-sweetened beverages on health ${ }^{(16-21)}$. However, limiting the food choices of SNAP recipients has been perceived by particular stakeholders (e.g. some anti-hunger advocates) as stigmatizing and unfair to low-income SNAP recipients ${ }^{(14)}$, and there is concern about the effectiveness and feasibility of placing limitations on the types of foods and beverages that can be purchased with SNAP benefits ${ }^{(22)}$. For instance, when New York City requested a waiver to limit the purchase of sugar-sweetened beverages with SNAP benefits, the USDA rejected this proposal due to concerns about the feasibility of monitoring the initiative's health impact and implementation at the retail level ${ }^{(23)}$. In our study, however, most survey respondents believed that EBT technology would make the implementation of this type of proposal feasible for retailers. More flexibility for USDA waivers is needed to allow states and municipalities to test and evaluate promising new strategies to improve nutritional health and prevent obesity among SNAP participants.

Providing financial incentives to purchase nutrientdense foods was a widely supported strategy in the present study although these types of programmes will likely incur additional costs. Programmes such as the USDAfunded Healthy Incentives Pilot in Massachusetts (which provides incentives to SNAP recipients at the point of sale to increase their purchase of fruits and vegetables) and privately funded initiatives that double the value of SNAP 
benefits at farmers' markets and some farm stands are favourable among SNAP participants and policy advocates, although their effects on increasing fruit and vegetable consumption have been marginal ${ }^{(24,25)}$. In the current economic climate, the national scale-up of these types of programmes may be challenging. There is also concern that farmers' markets are seasonal and geographically limited so that many SNAP participants would not benefit from this type of initiative. Although the percentage of SNAP dollars spent at farmers' markets increased by $94 \%$ between 2008 and 2009, purchases at these venues still accounted for only $0.009 \%$ of total SNAP transactions nationwide in $2009^{(26)}$.

The present study underscores the critical importance of pilot studies to examine diverse strategies to improve the nutritional health of SNAP recipients. Because the USDA has been unable to collect data on the purchases of SNAP recipients, knowledge of what foods and beverages are bought through the programme is limited. As a result, it has been difficult to assess which products are most frequently purchased with SNAP benefits. One strategy may be to encourage the USDA to collect data on the types of foods and beverages purchased with SNAP benefits to evaluate nutritional quality. Additionally, data on all food purchases would help to illuminate whether the programme is contributing to the obesity epidemic among recipients and would serve as a valuable tool for researchers to assess the programme's effectiveness and to evaluate policies and interventions aimed at strengthening nutrition in SNAP.

\section{Limitations}

The present study represents an initial effort to present an assessment of multiple stakeholders' views about innovative approaches to align SNAP participants' food and beverage purchases with the 2010 Dietary Guidelines for Americans. However, there are several limitations that must be acknowledged. First, there are three important stakeholder groups who were not represented in our study population: SNAP participants, SNAP retailers (particularly owners of small grocery stores) and the general public, which supports SNAP through federal taxes. However, we recently used a national polling service to study the views of SNAP participants and the general public, and found results similar to the survey of stakeholders $^{(27)}$. Among SNAP participants, 54\% supported removing programme benefits for sugary drinks; and this number increased to three out of four surveyed if the policy was paired with financial incentives to purchase healthy food. Among the general public, 77\% supported continued or increased funding for SNAP, but $69 \%$ supported removing sugary drinks (such as soda) from the list of SNAP-approved products. Similarly, surveys of SNAP retailers would be informative in understanding how changes in the programme's policies would affect their business and what support could be given to smaller SNAP retailers to stock healthier foods in their stores.

A second limitation of the study is the potential for selection bias from the convenience sample, where those who responded to the survey might possess a greater interest in changing SNAP policies than individuals who did not respond to the survey. Because study participants completed a web-based survey, we were unable to compare basic characteristics of study participants with those of survey non-respondents. This comparison would have helped to understand whether the study participants were representative of the general SNAP stakeholder groups. Second, some survey respondents ( $n$ 82) indicated they were not directly involved with the programme, making it difficult to quantify their knowledge or experience with SNAP. However, when these respondents were excluded from the analysis, the results of the study did not change (data not shown). Further, some sector categories were heterogeneous. For example, within the category of advocacy groups are anti-poverty organizations, sustainable agriculture groups and public health organizations, which might have very different opinions on an issue. Further research is needed to understand their views. Additionally, because of a low response rate from the food industry (including retailers and manufacturers), the survey results reflect an oversampling of other stakeholder groups. Thus, caution should be used in generalizing the study findings to the larger population of SNAP stakeholders.

\section{Conclusions}

Our assessment of the opinions of a broad range of stakeholder groups reveals that there is wide support for new approaches to improve the nutritional status of SNAP participants ${ }^{(15)}$. Given that one in seven Americans is now receiving SNAP benefits (nearly $50 \%$ of whom are children), the impact of the triple burden of food insecurity, obesity and chronic disease in this population highlights an urgent need to strengthen SNAP to address the challenge of eating healthily on a limited budget ${ }^{(1,2,7)}$. Further attention should be given to policies that strengthen retail requirements, foster marketing of healthy foods, create incentives for SNAP participants to access and purchase healthier foods, and limit the purchase of unhealthy foods with SNAP benefits. Pilot programmes should be supported that operationalize interventions identified in the current study to determine their effectiveness, feasibility and cost. Data collection about food purchased by programme recipients is critical to future policy development for the programme.

The research offers policy makers options to consider during deliberations for strengthening SNAP, a key component of the Farm Bill, the primary agricultural and food 
policy legislation that is reauthorized approximately every 5 years by the US Congress.

The findings from the present survey provide a foundation for more discussion about ways to reformulate SNAP now and in the future to alleviate hunger, promote the consumption of nutritious food and help prevent obesity among its beneficiaries. SNAP is a critical programme with the potential to enhance the diets of more than 44.7 million Americans. However, as currently configured, the programme is a missed opportunity to improve nutrition and prevent obesity for its participants. Aligning SNAP with national public health priorities is a matter of urgency to ensure a healthier future for the low-income beneficiaries of this vital federal nutrition assistance programme.

\section{Acknowledgements}

Sources of funding: This publication was supported by grant \#68813 from the Robert Wood Johnson Foundation through its Healthy Eating Research Program and grant \#455435 from the Aetna Foundation to the Center for the Study of the Presidency and Congress (CSPC) with S.J.B. as principal investigator. C.W.L. was supported by a National Institutes of Health (NIH) training grant (5 T32 CA009001-35). S.B.F. has participated in this research using personal time; her salary is paid, in part, from USDA SNAP-Ed funds through the State of California. The contents of the paper are solely the responsibility of the authors and do not necessarily represent the official views of the Robert Wood Johnson Foundation, the Aetna Foundation, the New America Foundation, CSPC, the NIH or the State of California. Conflicts of interest: The authors report no other potential conflicts of interest. Ethics: The study protocol was considered exempt by the Harvard School of Public Health Institutional Review Board. Authors' contributions: S.J.B., E.E.H. and C.W.L. contributed equally to this work. All authors contributed to the design of the study; E.E.H. and C.W.L. analysed the data; E.E.H. drafted the manuscript; all authors contributed to the critical revision of the manuscript. All authors contributed to the work, read and approved the final manuscript.

\section{References}

1. US Department of Agriculture, Food and Nutrition Service (2012) SNAP Monthly Data. http://www.fns.usda.gov/pd/ 34SNAPmonthly.htm (accessed March 2012).

2. Eslami E, Filion K \& Strayer M (2011) Characteristics of Supplemental Nutrition Assistance Program Housebolds: Fiscal Year 2010. Alexandria, VA: Office of Research and Analysis, Food and Nutrition Service, US Department of Agriculture.

3. Andrews M, Smallwood D (2012) What's Behind the Rise in SNAP Participation? Amber Waves. http://www.ers.usda. gov/AmberWaves/March12/Features/SNAPRise.htm (accessed March 2012).
4. Coleman-Jensen A, Nord M, Andrews M et al. (2012) Household Food Security in the United States in 2011. Economic Research Report no. ERR-141. Washington, DC: US Department of Agriculture, Economic Research Service.

5. Dinour LM, Bergen D \& Yeh MC (2007) The food insecurity-obesity paradox: a review of the literature and the role food stamps may play. J Am Diet Assoc 107, 1952-1961.

6. Gleason P, Rangarajan A \& Olson C (2000) Dietary Intake and Dietary Attitudes Among Food Stamp Participants and Other Low-Income Individuals. Princeton, NJ: Mathematica Policy Research, Inc.

7. Leung CW, Ding EL, Catalano PJ et al. (2012) Dietary intake and dietary quality of low-income adults in the Supplemental Nutrition Assistance Program. Am J Clin Nutr 96, 977-988.

8. Institute of Medicine (2005) WIC Food Packages: Time for a Change. Washington, DC: The National Academies Press.

9. US Department of Agriculture, Food and Nutrition Service (2011) Healthy Hunger-Free Kids Act of 2010. http:// www.fns.usda.gov/cnd/governance/legislation/CNR_2010.htm (accessed October 2011).

10. US Department of Agriculture, Food and Nutrition Service (2011) SNAP Name Change. http://www.fns.usda.gov/ snap/outreach/pdfs/toolkit/2011/Community/Basics/SNAP_ name.pdf (accessed August 2011).

11. Leung CW, Hoffnagle EE, Lindsay AC et al. (2013) A qualitative study of diverse experts' views about barriers and strategies to improve the diets and health of Supplemental Nutrition Assistance Program (SNAP) beneficiaries. J Acad Nutr Diet 113, 70-76.

12. US Department of Agriculture, Food and Nutrition Service (2012) Nutrition Education. http://www.fns.usda.gov/ snap/nutrition_education/ (accessed May 2012).

13. Leung CW, Willett WC \& Ding EL (2012) Low-income supplemental nutrition assistance program participation is related to adiposity and metabolic risk factors. Am J Clin Nutr 95, 17-24.

14. Institute of Medicine (2012) Accelerating Progress in Obesity Prevention: Solving the Weight of the Nation. Washington, DC: Institute of Medicine.

15. Center for the Study of the Presidency and Congress (2012) SNAP to Health: A Fresh Approach to Improving Nutrition in the Supplemental Nutrition Assistance Program. Washington, DC: Center for the Study of the Presidency and Congress.

16. Malik VS, Schulze MB \& Hu FB (2006) Intake of sugarsweetened beverages and weight gain: a systematic review. Am J Clin Nutr 84, 274-288.

17. Malik VS, Popkin BM, Bray GA et al. (2010) Sugar-sweetened beverages and risk of metabolic syndrome and type 2 diabetes: a meta-analysis. Diabetes Care 33, 2477-2483.

18. Mozaffarian D, Hao T, Rimm EB et al. (2011) Changes in diet and lifestyle and long-term weight gain in women and men. N Engl J Med 364, 2392-2404.

19. de Ruyter JC, Olthof MR, Seidell JC et al. (2012) A trial of sugar-free or sugar-sweetened beverages and body weight in children. $N$ Engl J Med 367, 1397-1406.

20. Ebbeling CB, Feldman HA, Chomitz VR et al. (2012) A randomized trial of sugar-sweetened beverages and adolescent body weight. $N$ Engl J Med 367, 1407-1416.

21. Qi Q, Chu AY, Kang JH et al. (2012) Sugar-sweetened beverages and genetic risk of obesity. N Engl J Med 367, 1387-1396.

22. Food Research and Action Center (2010) Coalition Statement on Preserving Food Choice in SNAP/Food Stamps. Washington, DC: Food Research and Action Center.

23. Shahin J (2011) Letter from Jessica Shahin, Associate Aministrator, Supplemental Nutrition Assistance Program to Elizabeth Berlin, Executive Deputy Commissioner, New York State Office of Temporary Disability Assistance. http://www.foodpolitics.com/wp-content/uploads/SNAPWaiver-Request-Decision.pdf (accessed March 2012). 
24. US Department of Agriculture, Food and Nutrition Service (2013) Healthy Incentives Pilot (HIP) Interim Report Summary. http://www.fns.usda.gov/ora/menu/Published/ SNAP/FILES/ProgramDesign/HIP_Interim_Summary.pdf (accessed July 2013).

25. Fair Food Network (2013) Double Up Food Bucks - 2012 Evaluation Report. http://www.fairfoodnetwork.org/sites/ default/files/FFN_DUFB_Evaluation_2012_sm_0.pdf (accessed July 2013).
26. Berkenkamp J \& Kastler M (2010) EBT at Farmers Markets: Initial Insights from National Research and Local Dialogue. Minneapolis, MN/Washington, DC: Institute for Agriculture and Trade Policy.

27. Long MW, Leung CW, Cheung LW et al. (2012) Public support for policies to improve the nutritional impact of the Supplemental Nutrition Assistance Program (SNAP). Public Health Nutr (Epublication ahead of print version). 